\title{
Patterns of host and flea communities along an elevational gradient in Colorado
}

\author{
S.P. Maher and R.M. Timm
}

\begin{abstract}
Patterns in community composition across a landscape are the result of mechanistic responses and species interactions. Interactions between hosts and parasites have additional complexity because of the contingency of host presence and interactions among parasites. To assess the role of environmental changes within host and parasite communities, we surveyed small mammals and their fleas over a dynamic elevational gradient in the Front Range in Colorado, USA. Communities were characterized using several richness and diversity metrics and these were compared using a suite of frequentist and randomization approaches. We found that flea species richness was related to the number of host species based upon rarefaction, but no patterns in richness with elevation were evident. Values of diversity measures increased with elevation, representing that small-mammal and flea communities were more even upslope, yet turnover in composition was not related to examined variables. The results suggest there are strong local effects that drive these small-mammal and flea communities, although the breadth of flea species is tied to host availability.
\end{abstract}

Key words: Siphonaptera, fleas, Rodentia, small mammals, species richness, host-parasite relationships.

Résumé : La répartition de la composition des communautés sur l'ensemble d'un paysage est le résultat de réactions mécanistes et d'interactions entre espèces. Les interactions d'hôtes et de parasites revêtent une complexité supplémentaire en raison de l'impondérabilité de la présence des hôtes, ainsi que des interactions de parasites. Afin d'évaluer le rôle des changements du milieu au sein de communautés d'hôtes et de parasites, nous avons étudié des petits mammifères et leurs puces sur un gradient altitudinal dynamique dans la chaîne frontale des Rocheuses, au Colorado, É.-U. Les communautés ont été caractérisées à l'aide de plusieurs paramètres de richesse et de diversité, qui ont été comparés en utilisant un ensemble d'approches fréquentistes et de randomisation. Nous avons constaté que la richesse spécifique des puces était reliée au nombre d'espèces d'hôtes reposant sur la raréfaction, mais aucune tendance de la richesse en fonction de l'altitude n'est ressortie. Les valeurs de mesures de la diversité augmentaient avec l'altitude, indiquant que les communautés de petits mammifères et de puces étaient plus équitables vers le haut, même si le renouvellement de la composition n'était pas relié aux variables examinées. Les résultats donnent à penser que de forts effets locaux contrôlent ces communautés de petits mammifères et de puces, bien que la diversité des espèces de puces soit associée à la disponibilité des hôtes. [Traduit par la Rédaction]

Mots-clés : Siphonaptera, puces, rongeurs, petits mammifères, richesse spécifique, relations hôte-parasite.

\section{Introduction}

Understanding drivers of patterns of species richness and diversity are key goals in ecological and biogeographical studies (Rosenzweig 1995; Ricklefs and Jenkins 2011). Models of community assembly can demonstrate underlying mechanisms that explain similarity in structure across taxonomic and functional groups (e.g., Caswell 1976; Connor and Simberloff 1979; Menge and Olson 1990; Kelt 1999; Kelt et al. 1999; Leibold and Mikkelson 2002; Emerson and Gillespie 2008; Thibault and Brown 2008). Macroecological patterns frequently are generated from historic processes including those on geological and evolutionary time scales (Brown 1995; Lomolino et al. 2006; Emerson and Gillespie 2008). Biotic interactions can influence local communities on shorter time scales through facilitation and limitation (Leibold et al. 2004; Urban 2011), with local environmental characteristics influencing aspects of occupancy and abundance as well (e.g., Reed et al. 2007).

Host-parasite relationships represent such a dynamic interplay between environmental constraints and biotic facilitation (Poulin
2001; Stanko et al. 2002; Collinge and Ray 2006; Krasnov et al. 2006c; Lafferty et al. 2006; Mostowy and Engelstädter 2011; Renwick and Lambin 2013). Generally, taxa will occur where environmental conditions are suitable and available, and these will be limited by resources and dispersal (Peterson et al. 2011). Parasites are then constrained to at least a subset of these conditions, but likely have additional resources, dispersal, and physiological limits (Poulin 1995, 2004; Combes 2001; Blakeslee et al. 2012; Hoberg and Brooks 2008; Krasnov et al. 2010a). Furthermore, the level of specialization of parasites may restrict distribution and abundance through resource availability (Combes 2001; Krasnov et al. 2007), as well as interactions with other parasite species (Krasnov et al. 2006a, 2006c). Changes in the host community have been shown to influence parasite community structure, yielding reduced pathogen prevalence in several systems (e.g., Ostfeld and Keesing 2000).

We examined a host-parasite community within a montane region of the Front Range in central Colorado, USA. Sampling small mammals and their fleas along an elevational gradient provided the opportunity to test several hypotheses of commu-

Received 30 October 2013. Accepted 25 March 2014.

S.P. Maher* and R.M. Timm. Department of Ecology and Evolutionary Biology and Biodiversity Institute, University of Kansas, 1345 Jayhawk Boulevard, Lawrence, KS 66045, USA.

Corresponding author: S.P. Maher (e-mail: smaher02@gmail.com).

*Present address: Environmental Science, Policy and Management, 140 Mulford Hall, University of California, Berkeley, Berkeley, CA 94720, USA. 
nity organization and assembly within a relatively homogenous habitat matrix with simultaneous changes in environmental conditions. First, because of known host-parasite relationships, we test for an association between flea and small-mammal richness. We expect flea richness measures to be positively correlated with measures of host richness (prediction 1a) (Krasnov et al. 2005, 2010a; Krasnov 2008) or, if there is no association, environmental conditions will explain patterns of flea richness (prediction 1b). Second, as previous work has demonstrated both increased flea richness (Ponce and Llorente 1993) and reduced flea richness (Eads and Campos 1983) at higher elevations, we predict that changes in host richness with elevation will explain patterns in flea richness, particularly after controlling for the number of individuals in a sample (prediction 2). Third, flea communities will be sensitive to changes in host community and environmental conditions along our elevational gradient and this will influence turnover in the flea community (Wenzel and Tipton 1966; Bossard 2006; Krasnov et al. 2006a, 2006b, 2006c, 2010b, 2010c). We predict that changes in the flea community can be explained by differences in elevation, which will act as a proxy for differences in temperature and precipitation (prediction $3 a$ ), and and turnover will be related to simultaneous turnover in the mammal community (prediction $3 b)$. Absence of such effects would suggest that local stochastic processes and species interactions drive flea community assembly.

\section{Materials and methods}

\section{Study area}

Rocky Mountain National Park (RMNP) in north-central Colorado, USA (Fig. 1), encompassing approximately 107556 ha, is a generally continuous protected area, including mountain meadows, tundra, and forests within its landscape; it receives approximately 3000000 visitors annually. Arapaho-Roosevelt National Forest (ARNF) is considerably larger (approximately 607050 ha) and includes areas adjacent east, west, and south of RMNP, extending down slope to the shortgrass prairie. It contains large tracks of forest and meadows interspersed with anthropogenic disturbance.

In 2007 and 2008, we sampled seven sites that ranged in elevation from 2180 to $3170 \mathrm{~m}$ (Fig. 1) between May and August. As flea communities have been observed to reflect habitat changes, we tried to maintain locations within similar vegetation communities. All sites but one were forested, with the dominant species of trees varying among elevations and local environments. Hollowell Park was not entirely forested and contained a large area of meadow, but was bookended by areas of tree cover. Pine species represented varied depending upon elevation, changing from ponderosa pine (Pinus ponderosa Douglas ex P. Lawson \& C. Lawson) at lower elevations, to Rocky Mountain lodgepole pine (Pinus contorta var. latifolia Engelm. ex S. Watson), and then to limber pine (Pinus flexilis E. James). Throughout the transect, Engelmann spruce (Picea engelmannii Parry ex Engelm.), silver spruce (Picea pungens Englem), western balsam fir (Abies lasiocarpa (Hook.) Nutt.), and Douglas spruce (Pseudotsuga menziesii (Mirb.) Franco) occurred, particularly in wetter areas.

\section{Sampling}

Each transect consisted of 60 traps: 30 LFATDG Sherman Live Traps $(7.62 \mathrm{~cm} \times 8.89 \mathrm{~cm} \times 22.86 \mathrm{~cm}), 10$ XLF15 Sherman Live Traps $(10.16 \mathrm{~cm} \times 1.43 \mathrm{~cm} \times 38.1 \mathrm{~cm}$; H.B. Sherman, Tallahassee, Florida, USA), 10 rat-sized snap traps, and 10 pitfall traps (approximately $10 \mathrm{~cm}$ diameter). Multiple trap types were used to maximize the diversity of mammals captured, particularly larger mammals such as woodrats (genus Neotoma Say and Ord, 1825) that can be too large to fit in smaller live traps. The arrangement of traps was 10 replicates of one LFATDG, one XLF15, one LFATDG, one snap trap, one LFATDG, and one pitfall. Traps were set 8-10 m apart along linear transects so that multiple vegetation classes could be sampled at a single site, but variation in elevation within any single site was minimal. Traps were checked in the morning and evening for four consecutive days in each year, then removed from the site. Mammals captured in live traps were marked on their pelage to avoid double-counting of captures, but individuals were not marked uniquely. After release of the individual, we examined bags for parasites that may have been dislodged or left the host during handling. Mammals were identified to species using Armstrong $(1987,2007)$ and Fitzgerald et al. (1994) as references. Voucher specimens are deposited at the University of Colorado Museum of Natural History in Boulder.

Individuals captured in snap traps and (or) those sacrificed were placed in an individual plastic bag and transported to a secure site for processing. Animals were removed from the bag (which was resealed immediately) and brushed for parasites for $2 \mathrm{~min}$. Parasites thus dislodged were placed in saline solution for storage until identification and testing for presence of Yersinia pestis (Lehmann and Neumann 1896) van Loghem, 1944, the bacterium that causes plague. Time spent searching for dislodged parasites was not included in the $2 \mathrm{~min}$ period. After brushing, we examined the sealed bag for additional parasites. Fleas were identified to species using Hubbard (1947) and Furman and Catts (1982) and were tested for Y. pestis DNA at the Centers for Disease Control (CDC) and Prevention, Fort Collins, Colorado, USA (Maher 2010).

Permits for this work were provided by the Colorado Division of Wildlife and RMNP; research protocols were approved by the University of Kansas Institutional Animal Care and Use Committee and RMNP. All procedures involving handling wild mammals followed ASM guidelines (Gannon et al. 2007).

\section{Analysis of richness}

We pooled host and flea data for each site between years and counted numbers of species of hosts $\left(\mathrm{SR}_{\text {host }}\right.$, where $\mathrm{SR}$ is species richness) and fleas ( $\left.\mathrm{SR}_{\text {flea }}\right)$ for each site. To assess issues of detectability (MacKenzie et al. 2006), both from the observation process of hosts and parasites and from the possibility of parasites leaving the host prior to handling, we calculated estimates of $\mathrm{SR}_{\text {host }}$ and $\mathrm{SR}_{\text {flea }}$, specifically mean Chao 1 and Chao 2 values, using default settings in ESTIMATES version 8.0 (Colwell 2006). Chao values and confidence limits (Chao 1984, 1987) are calculated through counts of singletons (single observations of a species) and doubletons (at least two observations of a species). The estimators have been shown to be robust in extrapolating to known values using a limited sample (Peterson and Slade 1998). For hosts and fleas, we found both estimators yielded identical values or there were broadly overlapping confidence intervals at each site for each group and therefore we report the Chao 2 estimates $\left(\mathrm{ChaO}_{\text {host }}\right.$ and $\left.\mathrm{Chao}_{\text {flea }}\right)$, respectively. Correlation tests were used to compare estimated richness to observed values, essentially examining whether there were effects of detectability. We excluded red squirrels (Tamiasciurus hudsonicus (Erxleben, 1777)) from these calculations because detection in traps was low, although they were observed or heard calling at all seven sites. In addition, we excluded snowshoe hares (Lepus americanus Erxleben, 1777) from the host community, as we focus solely on the rodent community. We tested for a relationship between elevation and occurrence of host species, for both $\mathrm{SR}_{\text {host }}$ and $\mathrm{Chao}_{\text {host }}$, using a generalized linear model (GLM with Poisson and gamma families, respectively) using $R$ version 3.0.1 ( $R$ Core Team 2013), where elevation was the recorded value at the beginning of each trap transect. Correlations between $\mathrm{SR}_{\text {host }}$ and $\mathrm{SR}_{\text {flea }}$ and between $\mathrm{ChaO}_{\text {host }}$ and $\mathrm{Chao}_{\text {flea }}$ were used to examine our first set of predictions.

To address our second prediction, we used several approaches. First, we compared $\mathrm{SR}_{\text {flea }}$, $\mathrm{ChaO}_{\text {flea }}$, and the number of fleas in the sample to the numbers of individual hosts sampled for parasites across sites using GLMs with Poisson, gamma, and Poisson families, respectively to determine if differential sampling of hosts among 
Fig. 1. Map depicting the location of Rocky Mountain National Park (designated in black) with respect to Roosevelt National Forest (dark gray) and Arapaho National Forest (light gray). The seven sample sites are shown over a digital elevation model of the region, with the outline of the park as a broken line.

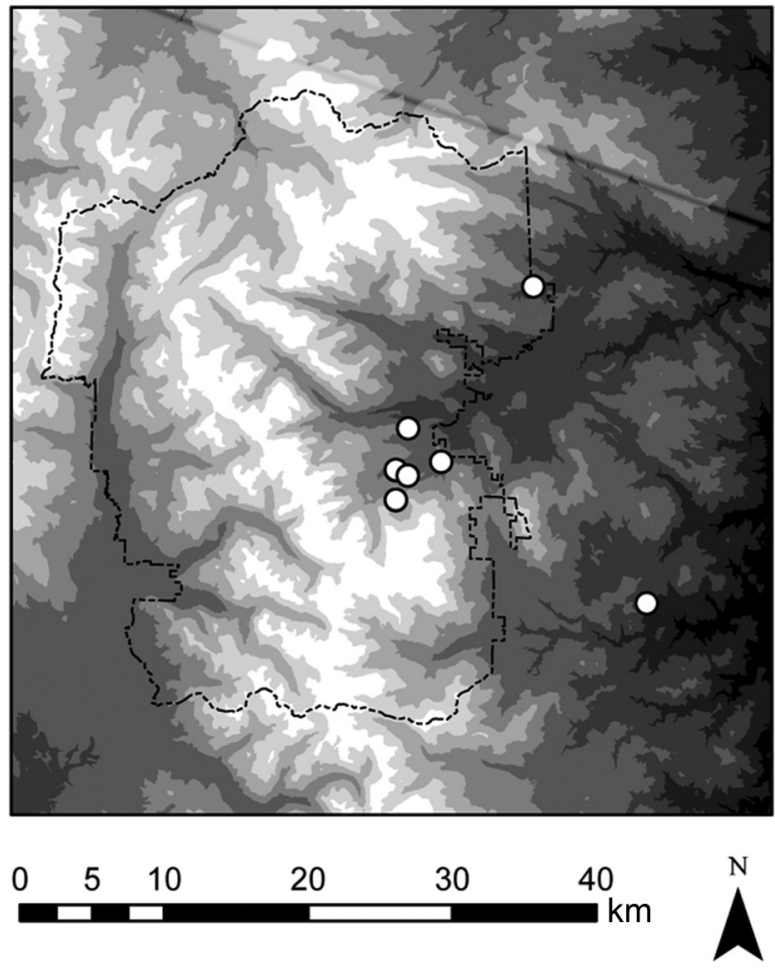

sites influenced these observations. We used a rarefaction to examine further potential effects of differential sampling among sites and the relationship between host and parasite richness. This step was achieved by sampling without replacement a subset of hosts and determining the sampled flea and host richness; the step was implemented in a VBA (Visual Basic for Applications) script written by S.P.M. (available upon request). To determine if localities differed in flea species richness, we examined overlap within \pm 2 SD around the rarefied means and compared subsets of $5,10,15$, and 20 hosts. If these values overlapped between sites, we concluded no difference in flea richness between them.

\section{Analysis of diversity}

We calculated mean Simpson reciprocal and mean Shannon indices for each site using ESTIMATES to assess simultaneously evenness and richness of the sampled host and flea species. Larger values of each index suggest more even communities, whereas values approaching zero represent unbalanced communities. To describe turnover between communities, we generated Bray-Curtis similarity and Chao-based Sørensen values between each pair of locations for hosts and fleas using default features in ESTIMATES and subtracted these values from unity to generate dissimilarity estimates. We tested for associations with elevation and diversity indices using GLMs with a gamma-link function.

Patterns of community structure with respect to changes in elevation and distance between sites were compared using multiple matrix regression with randomization (Wang 2013) within $R$ version 3.0.1 ( $R$ Core Team 2013). We calculated the difference in elevation between sites; geographic distance was calculated from the beginning of each transect to the beginning of each other transect. First, we compared changes in host community structure to changes in elevation and distance in geography. We then compared the flea community matrices to host community, distance in geography, and change in elevation.

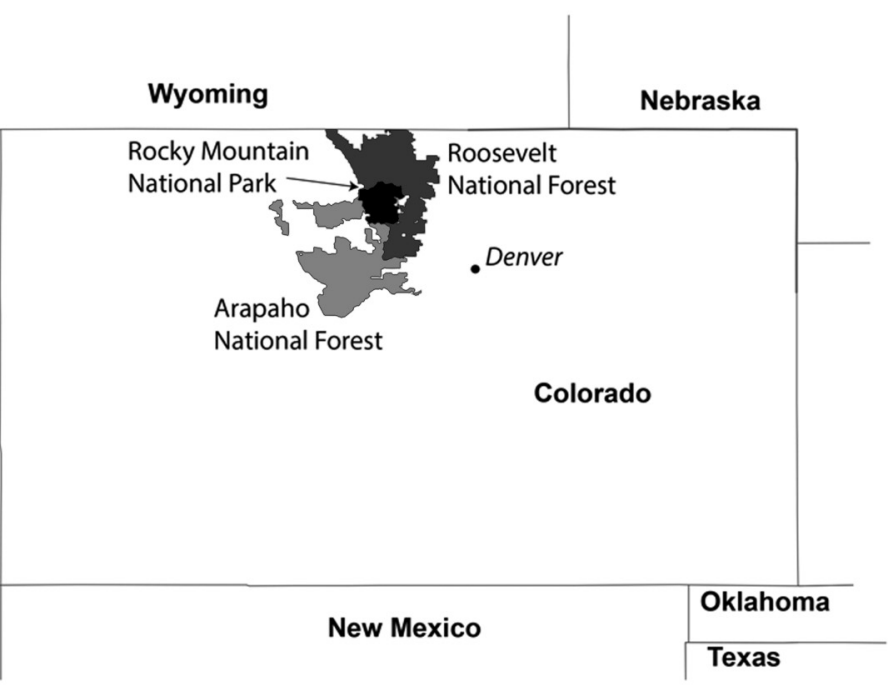

Legend

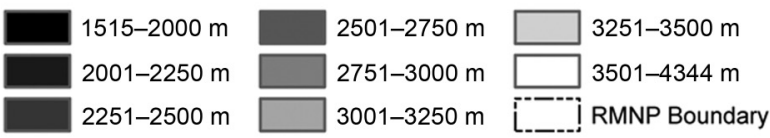

\section{Results}

\section{Field results}

We regularly captured eight species of rodents over the $990 \mathrm{~m}$ elevational gradient, in addition to incidental captures of two species-red squirrels and snowshoe hares (Table 1). Our efforts failed to capture shrews in any of our traps. In 2008, we detected bushy-tailed woodrats (Neotoma cinerea (Ord, 1815)) and Colorado chipmunks (Tamias quadrivittatus (Say, 1823)), which were not detected during 2007. Presumably, these observations are related to fewer captures of deer mice (Peromyscus maniculatus (Wagner, $1845)$ ) in 2008, which resulted in greater trap availability to capture other taxa. When years were pooled, deer mouse was ubiquitous and the dominant species both locally and overall.

Of the total host community captured in traps, we sampled 220 potential hosts for fleas-114 deer mice, 33 least chipmunks (Tamias minimus Bachman, 1839), 25 southern red-back voles (Myodes gapperi Vigors, 1830), 23 Uinta chipmunks (Tamias umbrinus J.A. Allen, 1890), 16 golden-mantled squirrels (Callospermophilus lateralis (Say, 1823)), 3 snowshoe hares, 3 Wyoming ground squirrels (Urocitellus elegans (Kennicott, 1863)), 1 bushy-tailed woodrat, 1 Colorado chipmunk, and 1 red squirrel. This subset of the host community represents individuals that were captured in snap traps, sacrificed, or those from which incidental captures of fleas after handling a live animal were taken. Details of flea occurrence records are shown in Table 2. We included 10 of the flea species in the analysis, excluding Hoplopsyllus (Euhoplopsyllus) glacialis (Taschenberg, 1880), which was found only on a single snowshoe hare, a species not included the mammal occurrence analysis owing to low capture rates.

The flea Aetheca wagneri (Baker, 1904) was the most common species, both in number and distribution, and was collected at all sites. The fleas Eumolpianus eumolpi (Rothschild, 1905) and Peromyscopsylla hesperomys (Baker, 1904) were common also and widely distributed, being found at 5 of 7 sites and 4 of 7 sites, respectively. The 
Table 1. Occurrence and number of unique individuals of small mammals captured or detected along the transect.

\begin{tabular}{|c|c|c|c|c|c|c|c|}
\hline Host species & $\begin{array}{l}\text { Roosevelt National } \\
\text { Forest }(2181 \mathrm{~m})\end{array}$ & $\begin{array}{l}\text { Cow Creek } \\
(2439 \mathrm{~m})\end{array}$ & $\begin{array}{l}\text { Hollowell Park } \\
(2588 \mathrm{~m})\end{array}$ & $\begin{array}{l}\text { Wind River } \\
(2630 \mathrm{~m})\end{array}$ & $\begin{array}{l}\text { Lower Boulder } \\
\text { Brook }(2714 \mathrm{~m})\end{array}$ & $\begin{array}{l}\text { Middle Boulder } \\
\text { Brook }(2818 \mathrm{~m})\end{array}$ & $\begin{array}{l}\text { Upper Boulder } \\
\text { Brook }(3171 \mathrm{~m})\end{array}$ \\
\hline Golden-mantled ground squirrel, Callospermophilus lateralis & 0 & 8 & 15 & 3 & 0 & 2 & 1 \\
\hline Southern red-backed vole, Myodes gapperi & 0 & 0 & 0 & 1 & 6 & 15 & 18 \\
\hline Bushy-tailed woodrat, Neotoma cinerea & 0 & 0 & 0 & 3 & 6 & 1 & 0 \\
\hline Deer mouse, Peromyscus maniculatus & 30 & 21 & 68 & 30 & 26 & 22 & 20 \\
\hline Least chipmunk, Tamias minimus & 0 & 12 & 10 & 1 & 6 & 0 & 13 \\
\hline Colorado chipmunk, Tamias quadrivittatus & 1 & 0 & 0 & 0 & 0 & 0 & 0 \\
\hline Uinta chipmunk, Tamias umbrinus & 0 & 4 & 0 & 5 & 10 & 9 & 0 \\
\hline Red squirrel, Tamiasciurus hudsonicus & 0 & 0 & 0 & 1 & 0 & 1 & 1 \\
\hline Wyoming ground squirrel, Urocitellus elegans & 0 & 0 & 13 & 0 & 0 & 0 & 0 \\
\hline
\end{tabular}

Table 2. Occurrence and abundance of flea species at sites along the elevational transect.

\begin{tabular}{|c|c|c|c|c|c|c|c|c|}
\hline Host & Flea & $\begin{array}{l}\text { Roosevelt National } \\
\text { Forest }(2181 \mathrm{~m})\end{array}$ & $\begin{array}{l}\text { Cow Creek } \\
(2439 \mathrm{~m})\end{array}$ & $\begin{array}{l}\text { Hollowell Park } \\
(2588 \mathrm{~m})\end{array}$ & $\begin{array}{l}\text { Wind River } \\
(2630 \mathrm{~m})\end{array}$ & $\begin{array}{l}\text { Lower Boulder } \\
\text { Brook }(2714 \mathrm{~m})\end{array}$ & $\begin{array}{l}\text { Middle Boulder } \\
\text { Brook (2818 m) }\end{array}$ & $\begin{array}{l}\text { Upper Boulder } \\
\text { Brook (3171 m) }\end{array}$ \\
\hline Snowshoe hare, Lepus americanus & Hoplosyllus (Euchoplosyllus) glacialis & 0 & 0 & 0 & 0 & 0 & 0 & 1 \\
\hline \multirow{7}{*}{ Southern red-backed vole, Myodes gapperi } & Aetheca wagneri & 0 & 0 & 0 & 0 & 1 & 0 & 5 \\
\hline & Catallagia decipiens (Rothschild, 1915) & 0 & 0 & 0 & 0 & 0 & 0 & 1 \\
\hline & Eumolpianus eumolpi & 0 & 0 & 0 & 0 & 0 & 0 & 1 \\
\hline & Megabothris abantis & 0 & 0 & 0 & 0 & 0 & 16 & 1 \\
\hline & Orchopeas sexdentatus (Baker, 1904) & 0 & 0 & 0 & 0 & 1 & 0 & 0 \\
\hline & Oropsylla idahoensis (Baker, 1904) & 0 & 0 & 0 & 0 & 0 & 0 & 1 \\
\hline & Peromyscopsylla hesperomys & 0 & 0 & 0 & 0 & 4 & 21 & 0 \\
\hline \multirow{3}{*}{ Bushy-tailed woodrat, Neotoma cinerea } & Aetheca wagneri & 0 & 0 & 0 & 0 & 1 & 0 & 0 \\
\hline & Eumolpianus eumolpi & 0 & 0 & 0 & 0 & 1 & 0 & 0 \\
\hline & Orchopeas sexdentatus & 0 & 0 & 0 & 0 & 1 & 0 & 0 \\
\hline \multirow[t]{7}{*}{ Deer mouse, Peromyscus maniculatus } & Aetheca wagneri & 0 & 9 & 3 & 20 & 26 & 12 & 3 \\
\hline & Catallagia decipiens & 0 & 0 & 0 & 1 & 1 & 0 & 1 \\
\hline & Epitedia wenmanni & 0 & 0 & 0 & 1 & 0 & 0 & 0 \\
\hline & Eumolpianus eumolpi & 0 & 0 & 1 & 0 & 0 & 0 & 0 \\
\hline & Malaraeus telchinus & 4 & 0 & 4 & 2 & 0 & 1 & 0 \\
\hline & Opisodasys keeni & 0 & 2 & 0 & 0 & 1 & 0 & 0 \\
\hline & Peromyscopsylla hesperomys & 0 & 1 & 0 & 14 & 7 & 4 & 0 \\
\hline Least chipmunk, Tamias minimus & Eumolpianus eumolpi & 0 & 0 & 1 & 3 & 5 & 0 & 10 \\
\hline \multirow{2}{*}{ Uinta chipmunk, Tamias umbrinus } & Aetheca wagneri & 0 & 0 & 0 & 1 & 0 & 1 & 0 \\
\hline & Eumolpianus eumolpi & 0 & 0 & 0 & 0 & 25 & 16 & 0 \\
\hline Wyoming ground squirrel, Urocitellus elegans & Oropsylla idahoensis & 0 & 0 & 2 & 0 & 0 & 0 & 0 \\
\hline Grand total & & 4 & 12 & 11 & 42 & 75 & 71 & 24 \\
\hline
\end{tabular}


remaining flea species associated with rodents were relatively uncommon but, with the exception of Epitedia wenmanni (Rothschild, 1904), occurred at more than one site. There was considerable variation in abundance of flea individuals at sites, with a minimum of 4 individuals and a maximum of 75 individuals (Table 2).

\section{Statistical results}

Observed local rodent species richness, $\mathrm{SR}_{\text {host }}$, varied from a minimum of two to a maximum of six, with a median of four (Table 3). Chao estimates of species richness, $\mathrm{Chao}_{\text {host }}$, were similar to $\mathrm{SR}_{\text {host }}\left(r=0.903, t_{[5]}=4.7061, P=0.005\right)$, but were slightly higher: minimum of two, maximum of eight, and median of five. Neither $\mathrm{SR}_{\text {host }}$ nor $\mathrm{ChaO}_{\text {host }}$ showed a strong statistical relationship to elevation $\left(F_{[1,5]}=2.143, P=0.203\right.$ and $F_{[1,5]}=4.567, P=0.086$, respectively; Figs. $2 \mathrm{~A}-2 \mathrm{D})$. $\mathrm{SR}_{\text {flea }}$ varied with respect to site (Table 3); $\mathrm{ChaO}_{\text {flea }}$ values also showed considerable variation with confidence intervals $( \pm 2 \mathrm{SD}$ ) quite broad for localities with high $\mathrm{SR}_{\text {flea }}$. The correlation between $\mathrm{SR}_{\text {flea }}$ and $\mathrm{ChaO}_{\text {flea }}$ values was high $\left(r=0.960, t_{[5]}=7.668, P=0.0006\right)$, but results also suggest that we may have undersampled some of the communities, particularly Wind River, Lower Boulder Brook, and Upper Boulder Brook (Table 3). Addressing our first hypothesis of correspondence between host and parasite richness measures, correlations between $\mathrm{SR}_{\text {host }}$ and $\mathrm{SR}_{\text {flea }}\left(r=0.918, t_{[5]}=5.186, P=0.003\right)$ and $\mathrm{Chao}_{\text {host }}$ and $\mathrm{Chao}_{\text {flea }}\left(r=0.827, t_{[5]}=3.292, P=0.022\right)$ were both significant.

In testing the hypothesis of richness values associated with elevation, we first examined whether there were effects of sample size and effort. The number of fleas in a sample was independent of the number of hosts sampled at that site $\left(F_{[1,5]}=0.001, P=0.920\right)$ and the GLM of flea richness and host sample size did not show significant patterns (observed: $F_{[1,5]}=0.605, P=0.472$; Chao: $F_{[1,5]}=$ $0.344, P=0.583$ ). We then rarified host data, yielding six sites that were essentially statistically indistinguishable from each other regarding rarefied $\mathrm{SR}_{\text {flea }}$ (Fig. 3). The Roosevelt National Forest site, which had one flea species, showed deviation from the other groups, although this might be due to a depauperate host community. When the number of hosts approached 20 in the rarefied sample, the estimate of $\mathrm{SR}_{\text {host }}$ reached an asymptote (Fig. 3). The plot of rarefied $\mathrm{SR}_{\text {host }}$ and estimated $\mathrm{SR}_{\text {flea }}$ shows that localities at higher elevations had equivalent rarefied $\mathrm{SR}_{\text {host }}$ to lower sites (Fig. 4) and that increases in rarefied $\mathrm{SR}_{\text {host }}$ yield larger estimates of $\mathrm{SR}_{\text {flea }}$.

Our third hypothesis examines how patterns of diversity change with elevation and whether turnover is predictable by such factors. We found mammal diversity was related significantly to elevation for both Simpson and Shannon indices $\left(F_{[1,5]}=\right.$ 11.26, $P=0.020$ and $F_{1,5}=13.08, P=0.015$, respectively; Figs. $\left.2 A-2 D\right)$. Host community differences with respect to distance and elevation between sample sites were not significant (Bray-Curtis multiple matrix regression with randomization (MMRR): $F=0.963$, $P=0.068$; Chao-based Sørensen MMRR: $F=1.780, P=0.346)$. For fleas, Shannon indices were positively related to elevation $\left(F_{[1,5]}=\right.$ 8.822, $P=0.031$; Fig. $5 A)$, but Simpson indices were $\operatorname{not}\left(F_{[1,5]}=2.23\right.$, $P=0.196$; Fig. 5B). The Simpson result may be due to a single large value (5.0) at Hollowell Park (Table 2) that also was associated with a large residual in the model (2.174). Removal of this point resulted in a significant model $\left(F_{[1,4]}=8.884, P=0.041\right)$. MMRR comparisons of flea community structure to host community, elevation, and distance were significant for Bray-Curtis $\left(F=8.2111, P=0.047, r^{2}=\right.$ 0.592) and Chao-based Sørensen $\left(F=9.470, P=0.021, r^{2}=0.626\right)$ values. In each case, geographic distance was the only significant predictor (Bray-Curtis: $t=4.326, P=0.032$; Chao-based Sørensen: $t=3.680, P=0.039$ ), but the coefficients (Bray-Curtis: $\beta=0.000021$; Chao-based Sørensen: $\beta=0.000029$ ) were very close to zero.

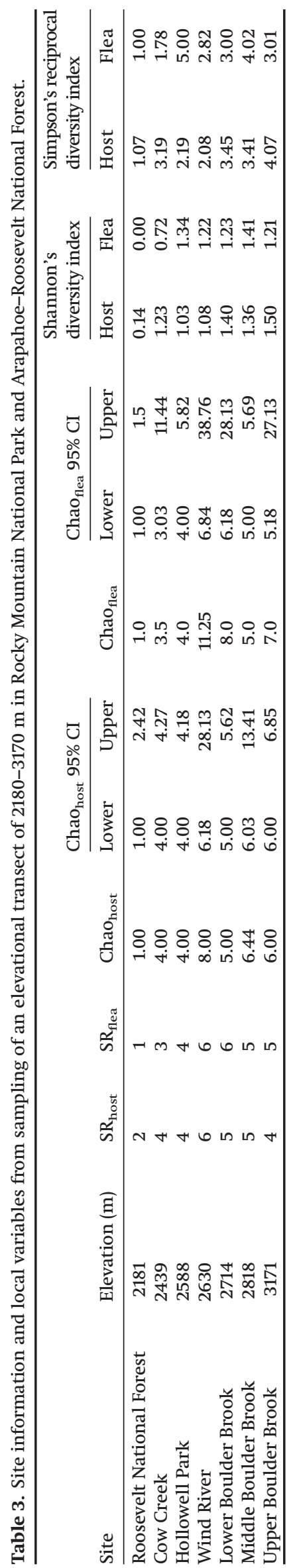

- Published by NRC Research Press 
Fig. 2. Plots representing the relationship between small-mammal species richness (SR) values and diversity indices with respect to elevation. The association with richness values $\mathrm{SR}_{\text {host }}(\mathrm{A})$ and $\mathrm{Chao}_{\text {host }}(\mathrm{B})$ were not statistically significant $\left(\mathrm{F}_{[1,5]}=2.143, P=0.203, r^{2}=0.30\right.$ and $F_{[1,5]}=$ 4.567, $P=0.086, r^{2}=0.477$, respectively), but both Shannon $(C)$ and Simpson $(D)$ diversity indices were associated with elevation $\left(F_{[1,5]}=13.08\right.$, $P=0.015$ and $F_{[1,5]}=11.26, P=0.020$, respectively).
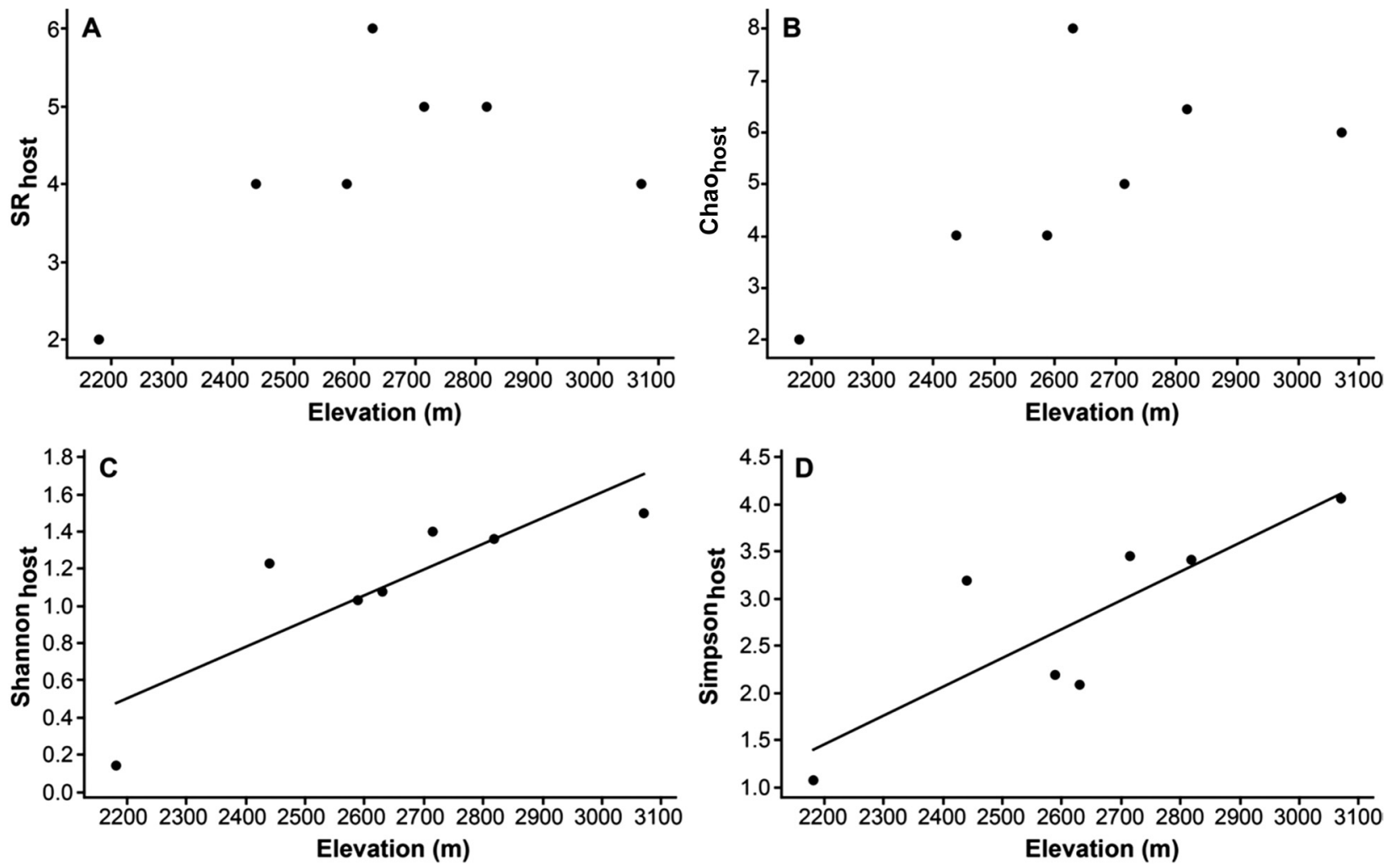

\section{Discussion}

Our survey of small mammals and fleas in the Colorado Rocky Mountains examined three hypotheses: (1) host and parasite richness relationships, (2) environmental influences on richness using elevation as a proxy, and (3) community turnover. We found a positive relationship between host and flea richness measures, but did not show an association of species richness with respect to elevation. As expected, the number of flea species trended with the number of host species when using rarefaction. Diversity indices were higher at higher elevations for both mammals and fleas, but variables reflecting geographic position and host community could not consistently explain patterns in turnover of flea community structure.

The positive relationship between small-mammal and flea richness measures supported the expected correspondence between host and parasite metrics (prediction 1a). This reflects the expectation that a broader host community will have a greater number of parasites (Krasnov et al. 2004; Krasnov 2008). Although smallmammal richness may not completely drive all aspects of flea richness (as our correlation values were less than unity), it is likely to mediate it to some regard because of host specificity and host associations of some fleas. In our data set, two species of fleas (A. wagneri and E. eumolpi) were over abundant on single host species and relatively sparse on the other well-sampled hosts (Table 1). Furthermore, some species (Megabothris abantis (Rothschild, 1905), Malaraeus telchinus (Rothschild, 1905), and Opisodasys keeni (Baker, 1896)) were associated with single hosts, and although our sample sizes are small, this is in part consistent with the literature on these species. Hubbard (1947) and Holland (1949) reported that M. telchinus is present on many hosts of various lineages and that 0 . keeni prefers deer mice, but they disagreed on host specificity of M. abantis, with Hubbard (1947) reporting a variety of hosts and

Holland (1949) reporting only deer mice. Our data show M. abantis from only southern red-backed voles; however, Eads and Campos (1983) reported it as uncommon on deer mice as well, so it is likely that it is not host specific. Linear models examining effects of host sampling effort on flea sample size and flea richness metrics were not significant, which was unexpected. We think this pattern reflects the variability in flea abundance and is not a reflection of the host community. Thus, given the presence of a specific host, a certain flea species may be more probable as part of the local community, but their abundance is driven by other factors.

With respect to patterns of richness and elevation, our rarefaction analysis demonstrated that after controlling for the number of individuals, there were no patterns of either small-mammal or flea richness with elevation, counter to prediction 2 . We expected to observe changes in small-mammal richness due to more harsh conditions at higher elevations, but rarefaction and our GLMs of small-mammal richness and elevation did not support such patterns. Instead of a reduction in richness metrics, we observed more even communities at higher elevations. This would increase the chance of drawing a more rich community when taking a small random sample of small mammals from the available pool, whereas an uneven host community would yield low estimates of host richness. Eads and Campos (1983) note lower flea richness at alpine locations and describe a small-mammal community dominated by deer mice (over $80 \%$ of their captures). Rarefaction of their data at our levels $(5,10,15$, and 20 host sample sizes) likely would yield low small-mammal richness estimates, but not impact measures of the flea richness.

The local diversity measures for fleas did trend positively with elevation, implying that environmentally stressful conditions (e.g., those at higher elevation) may influence the structure of flea communities to become more even (prediction $3 a$ ). Alternatively, 
Fig. 3. Plots representing results of rarefaction and species richness (SR). On the $x$ axis we show the number of hosts in the rarefied sample, while on the $y$ axis we show either the estimated $\mathrm{SR}_{\text {host }}$ (mean $\pm 2 \mathrm{SD}$ ) or the estimated $\mathrm{SR}_{\text {flea }}$ (mean $\pm 2 \mathrm{SD}$ ). Note that variations in estimates of $\mathrm{SR}_{\text {host }}$ at the three highest localities from our transect strongly overlap with all but Roosevelt National Forest (RNF) regardless of the size of rarefied sample. Similarly, variation in estimated $\mathrm{SR}_{\text {flea }}$ was high and mean values are not strongly associated with elevation.
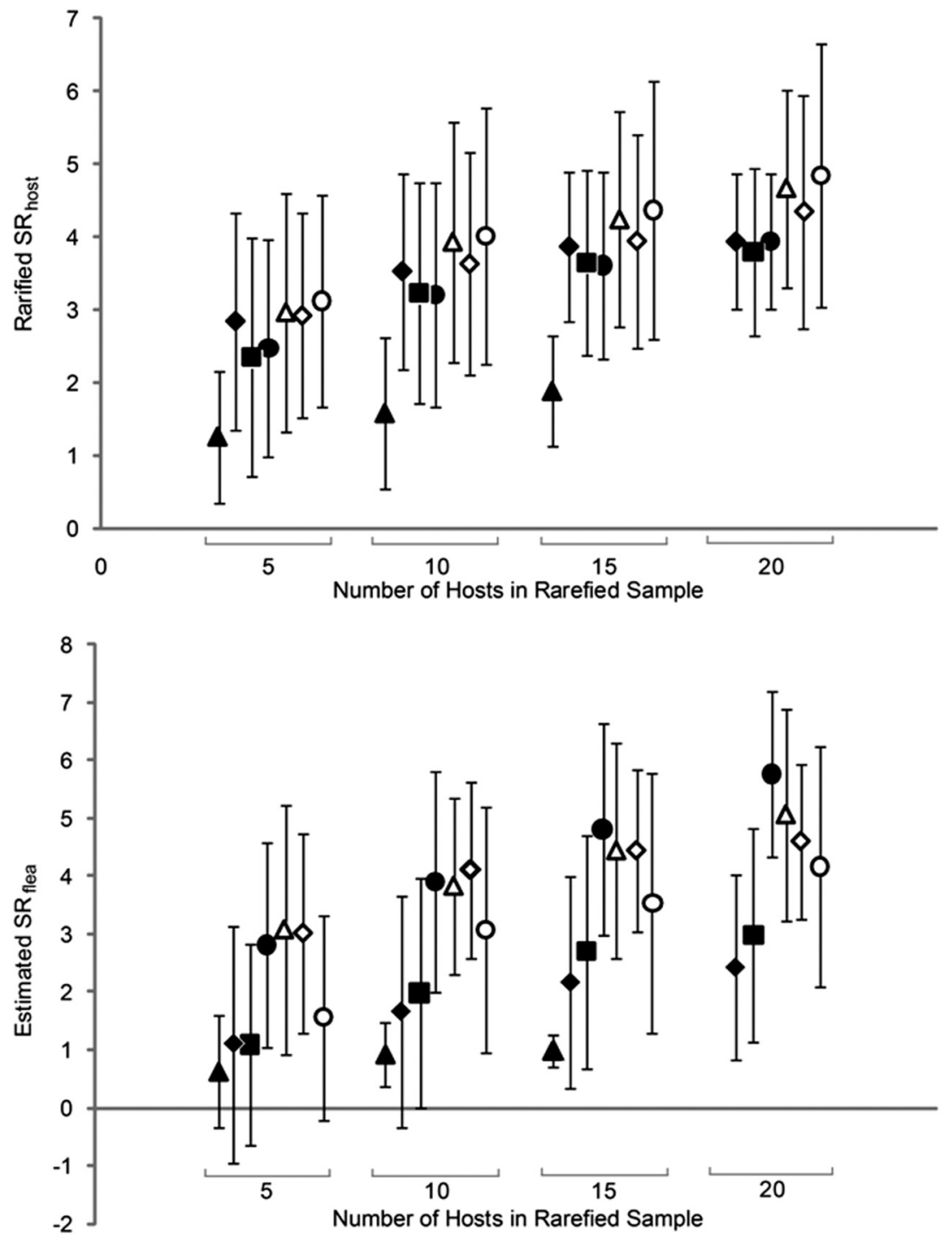

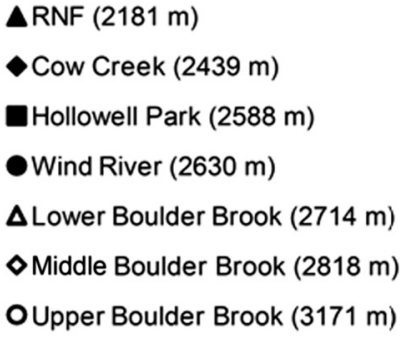

OUpper Boulder Brook (3171 m) this evenness may be an artifact of changes in local abundances within the small-mammal community, as we demonstrated a relationship between richness metrics. We expected turnover to be similar between communities (prediction $3 b$ ), but our data show that this is relatively independent. These results demonstrate differences in species occurrences within our gradient and suggest that there are overriding mechanisms which influence local patterns of composition. Poulin $(2003,2007)$ suggested that isolation by distance may be a common pattern in parasite community ecology and Krasnov et al. $(2010 b, 2010 c)$ note similar patterns for mammal-flea communities. Our results provide further support for this pattern and we expect that dispersal limitation may be key to understanding the differences between parasite communities. Furthermore, we suspect that species interactions within the parasite community (e.g., competitive exclusion) are not enough to drive patterns along our gradient and differences in microhabitat and environment influenced the flea communities (Krasnov 2008). Additional mechanisms, such as isolation due to topography or stochasticity may limit similarity across this landscape.

Previous work in the region by Eads and Campos (1983) focused on patterns of fleas with deer mice at higher elevations in RMNP, which allows for a comparison of observations and findings to our data set. Their data show similar patterns for the flea A. wagneri as in our survey, but we found the flea P. hesperomys more frequently and the flea 0 . keeni less often. Although we surprisingly found no significant pattern of flea richness and host sample size in our data set, Eads and Campos (1983) had a larger sample size of potential hosts, which would allow for detection of more rare species. Many of the flea species in their lists represented less than $1 \%$ of total fleas and these occurred on less than $1 \%$ of hosts. Differences in sampling techniques may account for missing flea species from our samples, such as fleas vacating a dead host before we could retrieve the trap. We attempted to control for this by using Chao estimators, which represent unsampled species in the data set, but our Chao values are well below values that we calculated for data provided byEads and Campos (1983). Although it also is possible that the flea community has become more depauperate in the 30 years between their first survey and our work, this is unlikely.

Perhaps the largest caveat of our analysis is the detectability of host and flea species within our study design. Chao-based measures can predict the expected number of species in a set (Peterson 
Fig. 4. Plots of rarified species richness of hosts $\left(\mathrm{SR}_{\text {host }}\right)$ and estimated species richness of fleas $\left(\mathrm{SR}_{\mathrm{flea}}\right)(\mathrm{mean} \pm 2 \mathrm{SD})$ show that as the estimate of $\mathrm{SR}_{\text {host }}$ increases so does $\mathrm{SR}_{\text {flea }}$, although error bars show significant overlap between sites.

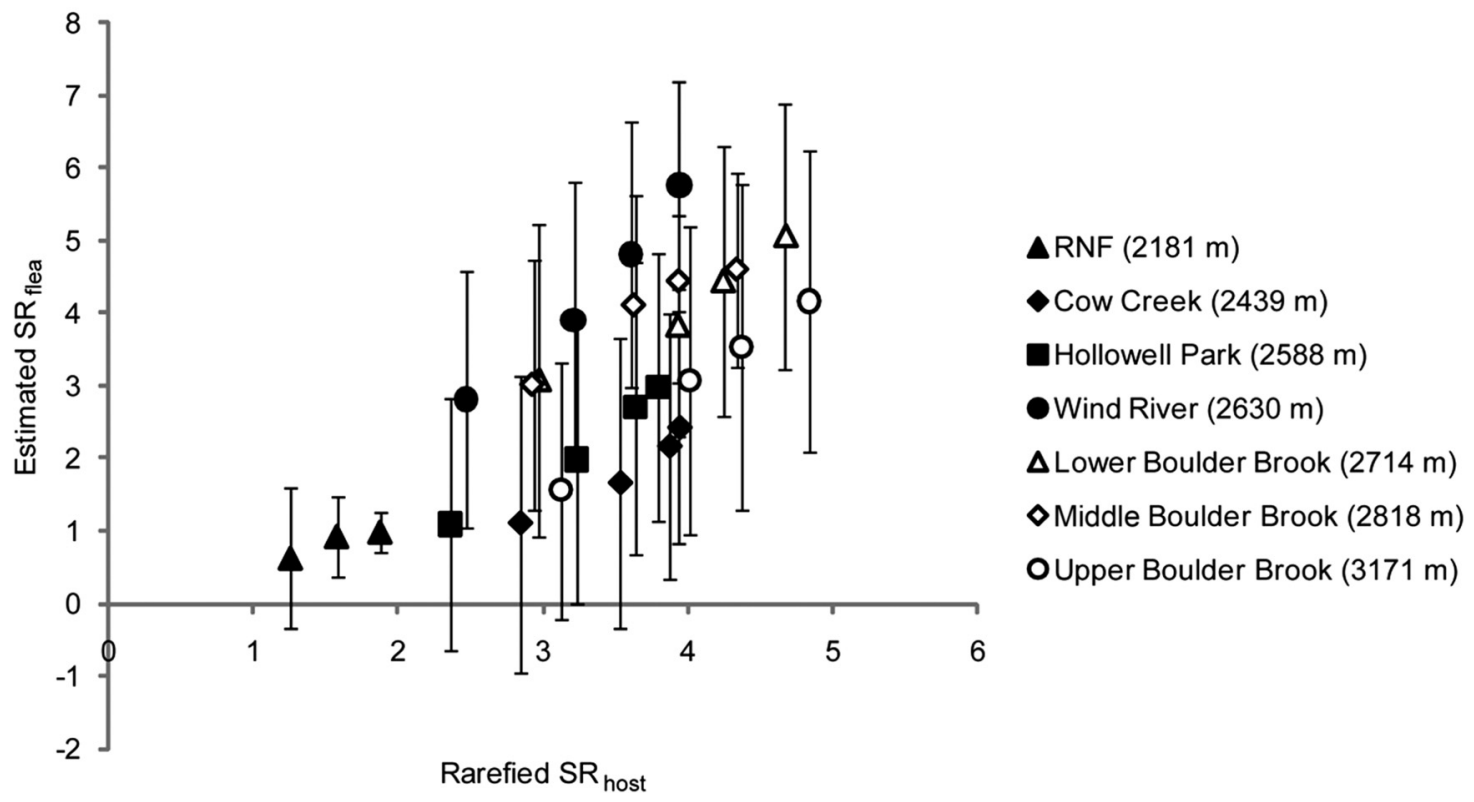

Fig. 5. Plots representing the relationship between flea diversity indices and elevation. Although Shannon indices (A) were positively related to elevation $\left(F_{[1,5]}=8.822, P=0.031\right)$, Simpson indices $(B)$ were $\operatorname{not}\left(F_{[1,5]}=2.23, P=0.196\right)$.

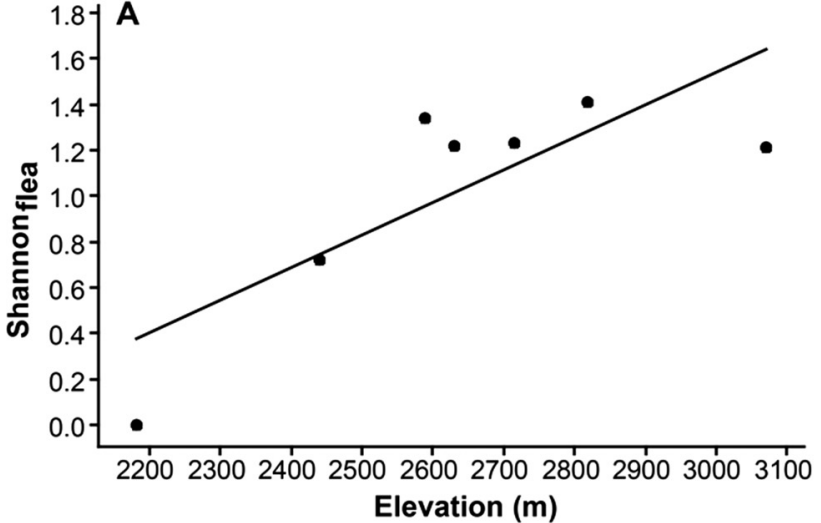

and Slade 1998), but cannot account for behavioral differences among species. For instance, if there is a regular pattern of departure of flea species from a dead host, we likely will not have a complete record of those that abandon early. Because of operational constraints, we were limited on host sampling procedures and length of surveys, which also may have reduced the overall flea species pool. Comparing our species list to Eads and Campos (1983), missing species are expected to be rare, which would reduce the magnitude of our diversity measures. The key aspect is whether such changes would detract from our main findings: that diversity increased with elevation and that flea turnover was independent of host turnover. Our measures would be biased if fleas that abandon early are located nonrandomly within our landscape, but this is unlikely. We are not familiar with studies that suggest flea species leave a carcass in a particular order and would expect that if individuals left the host it would be random. Furthermore, adding rare species would depress diversity values, but there is no reason to consider rare species to be nonrandom in their distribution, giving the patterns of host distribution.

The results of our survey represent important observations of flea and small-mammal community structure across a relatively short elevational gradient (approximately $990 \mathrm{~m}$ ). Using a variety

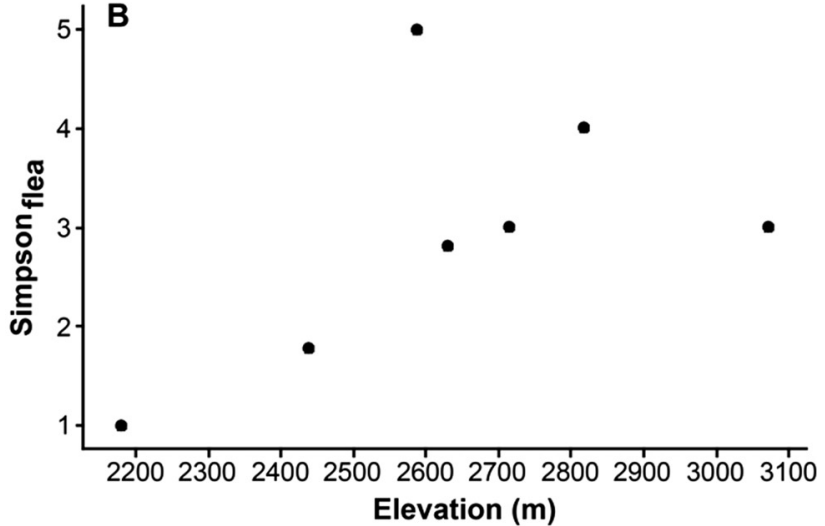

of analytical techniques, we identified that the richness of fleas is predictable from the host community and that changes in flea community are independent of changes in host community. Because fleas are vectors of plague (Gage and Kosoy 2005), understanding their ecology and community dynamics can provide insight into factors that lead to outbreaks (e.g., Cully et al. 1997; Eisen et al. 2006; Wimsatt and Biggins 2009). Changes in the host community may result in a reduction in the prevalence of a vector-transmitted pathogen (e.g., Ostfeld and Keesing 2000), but this pattern might not be universal (Salkeld et al. 2013). Quantifying isolating mechanisms of species across a landscape may help inform how plague spreads across this landscape.

\section{Acknowledgements}

K. Gage and his laboratory group, especially J. Montenieri, provided invaluable assistance and support in flea identification at CDC, Fort Collins. K. Sholty and K. Maiorana assisted in data collection in 2007. S.P.M. was supported by the American Society of Mammalogists Grants-in-Aid, Explorer's Club Redwood Creek Conservation Award, University of Kansas E. Raymond and Mary Hall Endowment, and the Rocky Mountain Nature Association Bailey Fellowship. J. Visty, J. Connor, and C. Yost provided logistical 
support and facilitated work in RMNP. K.B. Armitage, J.A. Esselstyn, A.T. Peterson, N.A Slade, the University of Kansas Mammal Discussion group, and anonymous reviewers provided comments on early drafts of the manuscript.

\section{References}

Armstrong, D.M. 1987. Rocky Mountain mammals: a handbook of mammal of Rocky Mountain National Park and vicinity. Colorado Associated University Press, Boulder, Colo., in cooperation with Rocky Mountain Nature Association, Estes Park, Colo.

Armstrong, D.M. 2007. Rocky Mountain mammals: a handbook of mammals of Rocky Mountain National Park and vicinity. University Press of Colorado, Boulder.

Blakeslee, A.M.H., Altman, I., Miller, A.W., Byers, J.E., Hamer, C.E., and Ruiz, G.M. 2012. Parasites and invasions: a biogeographic examination of parasites and hosts in native and introduced ranges. J. Biogeogr. 39(3): 609622. doi:10.1111/j.1365-2699.2011.02631.x.

Bossard, R.L. 2006. Mammal and flea relationships in the Great Basin Desert: From H.J. Egoscue's collections. J. Parasitol. 92(2): 260-266. doi:10.1645/GE3545.1. PMID:16729681.

Brown, J.H. 1995. Macroecology. University of Chicago Press, Chicago, Ill.

Caswell, H. 1976. Community structure: a neutral model analysis. Ecol. Monogr. 46(3): 327-354. doi:10.2307/1942257.

Chao, A. 1984. Nonparametric estimation of the number of classes in a population. Scand. J. Stat. 11(4): 265-270.

Chao, A. 1987. Estimating the population size for capture-recapture data with unequal catchability. Biometrics, 43(4): 783-791. doi:10.2307/2531532. PMID: 3427163.

Collinge, S.K., and Ray, C. (Editors). 2006. Disease ecology: community structure and pathogen dynamics. Oxford University Press, New York.

Colwell, R.K. 2006. EstimateS: statistical estimation of species richness and shared species from samples. Version 8 [computer program]. Available from http://viceroy.eeb.uconn.edu/estimates/ [accessed November 2009].

Combes, C. 2001. Parasitism: The ecology and evolution of intimate interactions. University of Chicago Press, Chicago, Ill.

Connor, E.F., and Simberloff, D. 1979. The assembly of species communities: chance or competition? Ecology, 60(6): 1132-1140. doi:10.2307/1936961.

Cully, J.F., Barnes, A.M., Quan, T.J., and Maupin, G. 1997. Dynamics of plague in a Gunnison's prairie dog colony complex from New Mexico. J. Wildl. Dis. 33(4): 706-719. doi:10.7589/0090-3558-33.4.706. PMID:9391954.

Eads, R.B., and Campos, E.G. 1983. Deer mouse, Peromyscus maniculatus, and associated rodent fleas (Siphonaptera) in the Arctic-Alpine life zone of Rocky Mountain National Park, Colorado. Great Basin Nat. 43(1): 168-174.

Eisen, R.J., Bearden, S.W., Wilder, A.P., Montenieri, J.A., Antolin, M.F., and Gage, K.L. 2006. Early-phase transmission of Yersinia pestis by unblocked fleas as a mechanism explaining rapidly spreading plague epizootics. Proc. Natl. Acad. Sci. U.S.A. 103(42): 15380-15385. doi:10.1073/pnas.0606831103. PMID: 17032761.

Emerson, B.C., and Gillespie, R.G. 2008. Phylogenetic analysis of community assembly and structure over space and time. Trends Ecol. Evol. 23(11): 619630. doi:10.1016/j.tree.2008.07.005. PMID:18823678.

Fitzgerald, J.P., Meaney, C.A., and Armstrong, D.M. 1994. Mammals of Colorado. Denver Museum of Natural History and University Press of Colorado, Niwot.

Furman, D.P., and Catts, E.P. 1982. Manual of medical entomology. 4th ed. Cambridge University Press, New York.

Gage, K.L., and Kosoy, M.Y. 2005. Natural history of plague: perspectives from more than a century of research. Annu. Rev. Entomol. 50: 505-528. doi:10. 1146/annurev.ento.50.071803.130337. PMID:15471529.

Gannon, W.L., Sikes, R.S., and the Animal Care and Use Committee of the American Society of Mammalogists. 2007. Guidelines of the American Society of Mammalogists for the use of wild mammals in research. J. Mammal. 88(3): 809-823. doi:10.1644/06-MAMM-F-185R1.1.

Hoberg, E.P., and Brooks, D.R. 2008. A macroevolutionary mosaic: episodic hostswitching, geographical colonization and diversification in complex hostparasite systems. J. Biogeogr. 35(9): 1533-1550. doi:10.1111/j.1365-2699.2008. 01951.x.

Holland, G.P. 1949. The Siphonaptera of Canada. Publ. 817, Tech. Bull. 70. Dominion of Canada, Department of Agriculture. Ottawa, Ont.

Hubbard, C.A. 1947. Fleas of western North America, their relation to the public health. Iowa State College Press, Ames.

Kelt, D.A. 1999. Assemblage structure and quantitative habitat relations of small mammals along an ecological gradient in the Colorado Desert of southern California. Ecography, 22(6): 659-673. doi:10.1111/j.1600-0587.1999.tb00515.x.

Kelt, D.A., Rogovin, K., Shenbrot, G., and Brown, J.H. 1999. Patterns in the structure of Asian and North American desert small mammal communities. J. Biogeogr. 26(4): 825-841. doi:10.1046/j.1365-2699.1999.00325.x.

Krasnov, B.R. 2008. Functional and evolutionary ecology of fleas. 1st ed. Cambridge University Press, Cambridge. doi:10.1017/CBO9780511542688.

Krasnov, B.R., Shenbrot, G.I., Khokhlova, I.S., and Allan Degen, A. 2004. Relationship between host diversity and parasite diversity: flea assemblages on small mammals. J. Biogeogr. 31(11): 1857-1866. doi:10.1111/j.1365-2699.2004. $01132 x$
Krasnov, B.R., Shenbrot, G.I., Khokhlova, I.S., and Poulin, R. 2005. Nested pattern in flea assemblages across the host's geographic range. Ecography, 28(4): 475-484. doi:10.1111/j.0906-7590.2005.04238.x.

Krasnov, B.R., Stanko, M., Khokhlova, I.S., Mošanský, L., Shenbrot, G.I., Hawlena, H., and Morand, S. 2006a. Aggregation and species coexistence in fleas parasitic on small mammals. Ecography, 29(2): 159-168. doi:10.1111/j. 2005.0906-7590.04353.x.

Krasnov, B.R., Stanko, M., Miklisova, D., and Morand, S. 2006b. Host specificity, parasite community size and the relation between abundance and its variance. Evol. Ecol. 20(1): 75-91. doi:10.1007/s10682-005-4731-5.

Krasnov, B.R., Stanko, M., and Morand, S. 2006c. Are ectoparasite communities structured? Species co-occurrence, temporal variation and null models. J. Anim. Ecol. 75(6): 1330-1339. doi:10.1111/j.1365-2656.2006.01156.x. PMID:17032365.

Krasnov, B.R., Shenbrot, G.I., Khokhlova, I.S., and Poulin, R. 2007. Geographical variation in the 'bottom-up' control of diversity: fleas and their small mammalian hosts. Global Ecol. Biogeogr. 16(2): 179-186. doi:10.1111/j.1466-8238. 2006.00273.x.

Krasnov, B.R., Matthee, S., Lareschi, M., Korallo-Vinarskaya, N.P., and Vinarski, M.V. 2010a. Co-occurrence of ectoparasites on rodent hosts: null model analyses of data from three continents. Oikos, 119(1): 120-128. doi:10. 1111/j.1600-0706.2009.17902.x.

Krasnov, B.R., Mouillot, D., Shenbrot, G.I., Khokhlova, I.S., and Poulin, R. $2010 b$. Deconstructing spatial patterns in species composition of ectoparasite communities: the relative contribution of host composition, environmental variables and geography. Global Ecol. Biogeogr. 19: 515-526. doi:10.1111/j.14668238.2010.00529.x.

Krasnov, B.R., Mouillot, D., Shenbrot, G.I., Khokhlova, I.S., Vinarski, M.V., Korallo-Vinarskaya, N.P., and Poulin, R. 2010c. Similarity in ectoparasite faunas of Palaearctic rodents as a function of host phylogenetic, geographic or environmental distances: which matters the most? Int. J. Parasit. 40: 807-817. doi:10.1016/j.ijpara.2009.12.002.

Lafferty, K.D., Dobson, A.P., and Kuris, A.M. 2006. Parasites dominate food web links. Proc. Natl. Acad. Sci. U.S.A. 103(30): 11211-11216. doi:10.1073/pnas. 0604755103. PMID:16844774.

Leibold, M.A., and Mikkelson, G.M. 2002. Coherence, species turnover, and boundary clumping: elements of meta-community structure. Oikos, 97(2): 237-250. doi:10.1034/j.1600-0706.2002.970210.x.

Leibold, M.A., Holyoak, M., Mouquet, N., Amarasekare, P., Chase, J.M., Hoopes, M.F., Holt, R.D., Shurin, J.B., Law, R., Tilman, D., Loreau, M., and Gonzalez, A. 2004. The metacommunity concept: a framework for multiscale community ecology. Ecol. Lett. 7(7): 601-613. doi:10.1111/j.1461-0248. 2004.00608.x.

Lomolino, M.V., Riddle, B.R., and Brown, J.H. 2006. Biogeography. 3rd ed. Sinauer Associates, Inc., Sunderland, Mass.

MacKenzie, D.I., Nichols, J.D., Royle, J.A., Pollock, K.H., Bailey, L.L., and Hines, J.E. 2006. Occupancy estimation and modeling: inferring patterns and dynamics of species occurrence. Academic Press, Burlington, Mass.

Maher, S.P. 2010. Spatial dynamics of mammals and their pathogens and parasites. Ph.D. dissertation, Ecology and Evolutionary Biology, University of Kansas, Lawrence.

Menge, B.A., and Olson, A.M. 1990. Role of scale and environmental factors in regulation of community structure. Trends Ecol. Evol. 5(2): 52-57. doi:10.1016/ 0169-5347(90)90048-I. PMID:21232321.

Mostowy, R., and Engelstädter, J. 2011. The impact of environmental change on host-parasite coevolutionary dynamics. Proc. Natl. Acad. Sci. U.S.A. 278(1716): 2283-2292. doi:10.1098/rspb.2010.2359.

Ostfeld, R.S., and Keesing, F. 2000. The function of biodiversity in the ecology of vector-borne zoonotic diseases. Can. J. Zool. 78(12): 2061-2078. doi:10.1139/ z00-172.

Peterson, A.T., and Slade, N.A. 1998. Extrapolating inventory results into biodiversity estimates and the importance of stopping rules. Divers. Distrib. 4(3): 95-105. doi:10.1046/j.1365-2699.1998.00021.x.

Peterson, A.T., Soberón, J., Pearson, R.G., Anderson, R.P., Martínez-Meyer, E., Nakamura, M., and Araújo, M.B. 2011. Ecological niches and geographic distributions. Princeton University Press, Princeton, N.J.

Ponce, H., and Llorente, J. 1993. Distribución de los Siphonaptera (Arthropoda; Insecta) de la Sierra de Atoyac de Álvarez, Gro., México. Anales del Instituto de Biología de la UNAM (Publicaciones Especiales), 11: 1-73.

Poulin, R. 1995. Phylogeny, ecology, and the richness of parasite communities in vertebrates. Ecol. Monogr. 65(3): 283-302. doi:10.2307/2937061.

Poulin, R. 2001. Interactions between species and the structure of helminth communities. Parasitology, 122(Suppl. 1): S3-S11. doi:10.1017/S0031182000016991. PMID:11442194.

Poulin, R. 2003. The decay of similarity with geographical distance in parasite communities of vertebrate hosts. J. Biogeogr. 30:1609-1615. doi:10.1046/j.13652699.2003.00949.x

Poulin, R. 2004. Macroecological patterns of species richness in parasite assemblages. Basic Appl. Ecol. 5(5): 423-434. doi:10.1016/j.baae.2004.08.003.

Poulin, R. 2007. Are there general laws in parasite ecology? Parasitology, 134: 763-776. doi:10.1017/S0031182006002150. PMID:17234043.

R Core Team. 2013. R: a language and environment for statistical computing. $R$ Foundation for Statistical Computing, Vienna, Austria. Available from http:/ www.r-project.org/. 
Reed, A.W., Kaufman, G.A., and Sandercock, B.K. 2007. Demographic response of a grassland rodent to environmental variability. J. Mammal. 88(4): 982-988. doi:10.1644/06-MAMM-A-109R.1.

Renwick, A.R., and Lambin, X. 2013. Host-parasite interactions in a fragmented landscape. Int. J. Parasitol. 43(1): 27-35. doi:10.1016/j.ijpara.2012.10.012. PMID: 23160021.

Ricklefs, R.E., and Jenkins, D.G. 2011. Biogeography and ecology: towards the integration of two disciplines. Trans. R. Soc. B Biol. Sci. 366(1576): 2438-2448. doi:10.1098/rstb.2011.0066.

Rosenzweig, M.L. 1995. Species diversity in space and time. Cambridge University Press, New York.

Salkeld, D.J., Padgett, K.A., and Jones, J.H. 2013. A meta-analysis suggesting that the relationship between biodiversity and risk of zoonotic pathogen transmission is idiosyncratic. Ecol. Lett. 16: 679-686. doi:10.1111/ele.12101. PMID: 23489376 .

Stanko, M., Miklisova, D., de Bellocq, J.G., and Morand, S. 2002. Mammal density and patterns of ectoparasite species richness and abundance. Oecologia, 131(2): 289-295. doi:10.1007/s00442-002-0889-5.

Thibault, K.M. and Brown, J.H. 2008. Impact of an extreme climatic event on community assembly. Proc. Natl. Acad. Sci. U.S.A. 105(9): 3410-3415. doi:10. 1073/pnas.0712282105. PMID:18303115

Urban, M.C. 2011. The evolution of species interactions across natural landscapes. Ecol. Lett. 14(7): 723-732. doi:10.1111/j.1461-0248.2011.01632.x. PMID: 21615660.

Wang, I.J. 2013. Examining the full effects of landscape heterogeneity on spatial genetic variation: a multiple matrix regression approach for quantifying geographic and ecological isolation. Evolution, 67: 3403-3411 doi:10.1111/evo. 12134. PMID:24299396.

Wenzel, R.L., and Tipton, V.J. (Editors). 1966. Some relationships between mammal hosts and their ectoparasites. In Ectoparasites of Panama. Field Museum of Natural History, Chicago, Ill. pp. 677-723.

Wimsatt, J., and Biggins, D.E. 2009. A review of plague persistence with special emphasis on fleas. J. Vector Dis. 46(2): 85-99. PMID:19502688. 